\title{
Desenhando com palavras: a terra viva do sertão euclidiano
}

\author{
Rodrigo Lemos Simões ${ }^{1}$ \\ Lúcia Lucas da Rosa ${ }^{2}$
}

\begin{abstract}
Resumo: Este artigo examina a geopoética contida na narrativa euclidiana a respeito do sertão nordestino, tendo como base o livro Os sertões. Obra original e inquietante foi responsável por trazer outro olhar sobre o interior do país, apresentando aos seus leitores um Brasil profundo onde as utopias de progresso e civilização encontravam a resistência tanto nos homens como na terra. Homem de letras e ciências, designado para acompanhar o episódio final protagonizado pelo exército nacional que combatia os sertanejos na vila de Canudos, interior da Bahia, acabou por deparar-se com questões sociais relacionadas ao abandono por parte do Estado e as intempéries da terra. Crítico e reflexivo teve que refazer muitos dos seus conceitos sobre as transformações por que passava o Brasil naquele período, em especial da vida em locais onde o meio físico se apresenta de forma tão intensa como é o caso do sertão baiano. Vista de forma integral o cenário descrito pelo autor vai além da aridez com que se construiu ao longo dos anos a imagem feita sobre o sertão e o sertanejo, pintando com palavras a transformação da natureza no nordeste do país.
\end{abstract}

Palavras-chave: Canudos. Sertão. Geopoética. Terra. Natureza.

\section{Drawing with words: the living land of Euclidean backlands}

Abstract : This paper examines the geopoetics in Euclidean narrative about the northeastern backlands, based on the book Rebellion in the Backlands. This original and unsettling work was responsible for bringing a different view of the countryside of the country, presenting its readers a deep Brazil, where progress utopias and civilization encountered resistance in both men and on earth. A man of letters and sciences, designated to accompany the final episode featured by the national army that fought the people in the backlands in the village of Canudos, in the countryside of Bahia, he was eventually faced with social issues related to the abandonment by the state and the earth resistance. Critical and reflexive, he had to redo many of his concepts on

\footnotetext{
${ }^{1}$ Licenciado em História pela Pontifícia Universidade Católica do Rio Grande do Sul (1995), Mestre em História pela Pontifícia Universidade Católica do Rio Grande do Sul (2000) e Doutor em Educação pela Pontifícia Universidade Católica do Rio Grande do Sul (2013). Professor Adjunto e Coordenador do Curso de Licenciatura em História da Universidade Luterana do Brasil.

${ }_{2}^{2}$ Possui Doutorado (2012) e Mestrado (1996) em Letras pela Universidade Federal do Rio Grande do Sul-UFRGS, área de Literatura Brasileira, Especialização em Reconstruindo o ensino de língua e literatura pelo Centro Universitário La Salle (1998) e graduação (1988) em Letras pela Pontifícia Universidade Católica do Rio Grande do Sul-PUC-RS. Atualmente é coordenadora do curso de Letras no Centro Universitário La Salle - Unilasalle, Canoas-RS, professora adjunta no curso de Letras e Coordenadora Institucional do PIBID/Capes (Programa Institucional de Bolsas de Iniciação à Docência).
}

\begin{tabular}{|l|l|l|l|l|} 
Textura & Canoas & v. 19 n.40 & p.251-267 & maio/ago. 2017 \\
\hline
\end{tabular}


the changes that Brazil was going through in that period, especially of life in places where the physical environment is so intense as in the case of the backlands of Bahia. In full, the scenario described by the author goes beyond the aridity in which the image made on the backlands and the people from the hinterland has been built over the years, painting with words the transformation of nature in the northeast of the country.

Keywords : Canudos. Backlands. Geopoetics. Earth. Nature.

\section{O SERTÃO DOS ENCONTROS}

Publicado no ano de 1902, Os Sertões, livro escrito por Euclides da Cunha trouxe o Brasil aos brasileiros. O Brasil interiorano, castigado pelo tempo e pelos homens, onde o abandono e a ausência do Estado nos primórdios da República (CARVALHO, 1997; MIR, 2004) fazia-se sentir nos lugares longínquos, de pessoas e terras entregues à própria sorte ou aos caprichos dos poderosos. Estes, mormente interessados na manutenção do poder, desfrutavam da violência coagindo e explorando o trabalho e a fé dos humildes, em troca de uma proteção quase feudal, onde vínculos de honra, gratidão e obediência eram construídos e perpetuados tais quais os dias de seca e jejum na aridez do sertão. A eles restavam a crença e a fé no porvir, a esperança de ter o corpo e a alma acalentados em dias de bonança que pareciam nunca chegar. No Estado republicano recém-formado o hiato que separava o litoral, filho rico e pródigo da nação, que não se reconhece no atraso da crendice e da superstição do Brasil profundo, é o legado de um Império soturno numa América que se transformara. "O litoral virado de costas para o sertão, eis a questão euclidiana" (SOUZA, 2009, p. 109), onde toda eloquência expressa no discurso dos exegetas do novo regime não se efetivou em forma de mudança na vida dos desventurados. Estes continuaram a triste sina dos filhos do sertão, onde o martírio do homem nasce do martírio secular da terra... (CUNHA, 1998, p. 63).

Em meio à força dos acontecimentos que sacudiram o país naquele fim de século (a abolição da escravidão, a imigração, o fim do Império, a proclamação da República, as revoltas regionais, etc.), a horda dos desprovidos. No sertão baiano, despossuídos e descuidados, homens e mulheres seguiam os passos do Conselheiro que, de um vilarejo a outro ia angariando mais fieis para sua causa. Pregador do sertão, homem das rezas e ladainhas, mas também das prédicas que atravessaram o século e continuam ecoando em nossa memória. Afinal, quem nunca ouviu dizer que "o sertão vai virar mar e o mar vai virar sertão"? Antônio Vicente Mendes Maciel, ou simplesmente Antônio Conselheiro, tornou-se uma liderança importante para 
os sertanejos, passando a vagar pelos sertões do Cariri, uma região árida onde os limites de diferentes Estados brasileiros encontram-se física $\mathrm{e}$ espiritualmente através da peregrinação dos penitentes e flagelados. Foram estes os fieis do beato. Vindos de muitos lugares, eram camponeses desprovidos e vencidos pela sorte, escravos recém-libertos, pobres e excluídos de todo tipo, aqueles a quem a República virou as costas. Ele mesmo, um desconcertante exemplo da necessidade de se buscar através da fé aquilo que não se encontrava na matéria, na vida dura e por vezes caprichosa, expressando através da renuncia a incompreensão e a inconformidade com os resultados do destino.

Doutro lado, Euclides da Cunha, o Homem de ciências e letras que chega ao sertão com o intuito de noticiar os dias que antecedem o fim trágico do beato e dos seus seguidores. Impregnado da crença no progresso pela ciência, tendo o positivismo contiano como alicerce, via-o de forma depreciativa, pejorativa, como sendo o pressuposto do atraso, "[...] desqualificando a terra e a humanidade a ela relacionada, reconhecendo neles a impossibilidade de qualquer desenvolvimento rumo à civilização" (OLIVEIRA, 2002, p. 512). Mas que destino é esse que faz encontrarem-se tão diferentes tipos no sertão baiano? De um lado o beato, tido como louco, um santarrão acusado de amotinar-se em sua cidadela contra a República recém-feita. De outro o intelectual, o engenheiro-escritor que partiu ao front contratado para acompanhar a evolução dos acontecimentos, e que já tinha por feição política uma predisposição a ver nos fatos a debacle da civilização e o repúdio a nova ordem política que se instaurara no país. Euclides e o Conselheiro nunca se encontraram em vida, porém, ambos foram marcados de forma indelével pela força da natureza do sertão. Terra viva, presente e penetrante que fez da vida a busca incessante pela sobrevivência. Terra incógnita, barbaramente estéril, maravilhosamente exuberante (CUNHA, 1998, p. 55), desenhada com palavras no texto euclidiano. Dessa forma, ganham destaque em nossa história, dois homens polêmicos, errantes, com propósitos diferentes: o personagem Antônio Conselheiro - líder religioso, que pregava ensinamentos por onde passava e o autor Euclides da Cunha - observador atento das dificuldades e organização comunitária no sertão.

Euclides da Cunha e Antônio Conselheiro têm trajetórias diferentes. Enquanto o primeiro vivia de forma única e previsível, com a família e o seu trabalho reconhecido socialmente, o segundo vagava entre os povoados, caminhando e arrebanhando seguidores. Ambos saem de seus locais de origem, porém em situações contrárias: um está ali provisoriamente, o outro 
segue rumo ao desconhecido, mas em ambos os casos, a palavra adquire força para permanência ou para expulsão. Euclides da Cunha foi pioneiro no tema e na técnica descritiva, tradição que, mais tarde, foi seguida por autores consagrados na literatura brasileira, como Graciliano Ramos, Rachel de Queiroz e J. Guimarães Rosa, autores que fazem do movimento interação mais que controle sobre espaço, com personagens que adquirem nas diversas suas reflexões antropológicas possíveis. No mesmo sentido, Bouvet destaca a importância deste tipo relação físico/intelectual na criação de significados:

\begin{abstract}
Le mouvement, considéré comme le pincipe premier de la pensée, gouverne également le rapport à l'espace en cela qu'il favorise l'interaction avec le paysage, l'adaptation à l'environnement plutôt que la maîtrise du territoire. C'est précisément ce va-et-vient entre le mouvement physique et le mouvement intellectuel qui crée le sens. (BOUVET, 2006, p. 47).
\end{abstract}

Sendo o Brasil um país novo em relação aos Estados europeus, essa literatura que remonta a terra sob o ponto de vista crítico, acabou por aproximar o leitor ao seu país, repensando-o e conduzindo a novas formas de ver e sentir o Brasil. A literatura contribui neste sentido, notadamente após a publicação de Euclides da Cunha.

\title{
UMA NOVA COMUNIDADE
}

Em seus estudos a respeito de o "ciclo euclidiano", Lícia Soares de Souza identifica aspectos da poética histórica dando origem à "[...] geração de textos meio fictícios, meio reais, o que significa exatamente a construção de mundos possíveis, a partir do fenômeno extratextual. A poética histórica autoriza esse ser textual híbrido, uma herança euclidiana, sem sombra de dúvida". (SOUZA, 2007, p. 78). De um modo geral, temos que a narrativa em torno da terra tem trazido muitas provocações à literatura e aos sonhos humanos na medida em que permite reconstrução de vida. Poética da terra, fonte primeva de todas as manifestações culturais e literárias (SOUZA, 2009), é dela a ideia de pertencimento a um lugar, a um grupo ou até mesmo a um ideal de luta e novas formas de relacionamento social. A terra demarca os territórios e imprime força de posse a determinadas pessoas, bem como, marca os despossuídos, os viajantes e aqueles que se identificam com o local. Não é 
em vão que o primeiro capítulo de Os Sertões, de Euclides da Cunha, se intitule $A$ terra, uma vez que assim o autor se identifica com o lugar e diz ao leitor de onde está falando. Inicialmente, o mapa é descrito de baixo para cima: "O planalto central do Brasil desce, nos litorais do sul, em escarpas inteiriças, altas e abruptas" (CUNHA, 1998, p. 11). Desta paisagem, minuciosamente descrita, chega ao sertão para marcar o espaço e diferenciá-lo de todos do país, em lugares "[...] evitados pelas vagas humanas" (CUNHA, 1998, p. 17), mostrando o quanto a rudeza da paisagem solidifica o cenário de toda a narração que se segue. Para Souza (2012), nas relações entre o homem e a terra é expressa através de sinais de rede bastante específicos, onde se pode observar a dialética entre a errância e a necessidade de raízes. Segundo a autora:

\begin{abstract}
La déterritorialisation devient le premier palier structurel des récits représentant les luttes contre la colonisation. Ainsi, les descriptions quasi scientifiques de la nature dévoilent les combats explicites de l'homme contre les intempéries et des climats rudes, et toutes ses tentatives d'aménagement en vue d'assurer sa survie. Ces descriptions relatives à l'action de l'homme sur la nature peuvent fonctionner comme des mises en abîme "éclatées", quand elles retardent le dénouement des conflits, et "concentrées" qui servent de base signifiante pour prédire les vraies luttes qui se dérouleront entre les populations naturelles et sauvages et les populations dites civilisées. (SOUZA, 2012, p. 1).
\end{abstract}

No caso de Euclides da Cunha, o sobrevoo pelo sertão evidencia o inóspito e improvável em relação à vida humana em condições climáticas tão adversas. Do uso de vocábulos como pedra, lajedos, solo, capa de areia, áridos, agreste, esgalhos, deserto, caatinga, granito, lagoas mortas, espectros de árvores, pedra seca e outros mais para chegar às expressões "filhos do deserto" e "monumentos de uma sociedade obscura" (CUNHA, 1998, p. 19). Todo o quadro revela ambiente hostil ao homem e à vida digna, tudo em ruínas e em estado de melancolia. A dureza do solo, agravada pelo aquecimento do sol em contrapartida a tempos de intensa chuva caracterizam o local como uma espécie de violência natural que vão dos "verões queimosos" aos "invernos torrenciais" (CUNHA, 1998, p. 21). Sobressai-se a descrição de um espaço hostil e por vezes, inóspito ao homem, onde a terra forja os tipos humanos. É o solo que propicia estilos de vida e, segundo o autor, é ele que revela o homem, como, ao final de uma descrição da paisagem, conclui: "Algumas denotam um esforço dos filhos do sertão" (CUNHA, 1998, p. 19). Neste caso, convenciona 
o sertão como base e manutenção de vida e, por isso, todas as dificuldades advindas dele e a imobilidade presente na sua permanência em meio a tantas dificuldades em suas paisagens atormentadas pela seca. A proximidade com o estilo de deserto se dá tanto pelo clima e ausência de vegetação quanto pelo modo de vida exigido do homem ali situado. Para Cordeiro (CORDEIRO, 2005, p. 110), o sertão brasileiro é descrito por Euclides como "um cenário amplo, complexo e intrigante, que mediante um método apropriado de abordagem, ajudaria a compreender a história e o destino do país." Mas é em primeiro lugar um sertão imenso dentro do habitante, um sertanejo que vira qualificativo do lugar e suas precárias condições, fixado na terra e na conformidade de assim o ser. Ausência? Desconhecimento? Sertão pela primeira vez desvelado através da narrativa euclidiana que, para Chaui inova uma vez que:

\begin{abstract}
Substituindo Deus e o Diabo pela ciência, isto é, pelo estudo do clima, da geologia e da geografia, a descrição de Euclides é duplamente impressionante: em primeiro lugar, pela força literária do texto, mas em segundo lugar, porque ela poderia ser lida como o avesso épico e dramático da descrição idílica de Pero Vaz, em cuja carta o sertão era apenas adivinhado e permanecia invisível. (CHAUI, 2001, p. 67).
\end{abstract}

Um livro que nasceu da pretensão de descrever um episódio inusitado aos olhos do observador provisoriamente situado em Canudos, como um desabafo ao enviar anotações para publicação na imprensa, tornou-se um grande clássico e lançou seu autor ao cenário dos grandes escritos em língua portuguesa. Heterogêneo, o texto compõe "[...] num arranjo dialógico radical dos discursos, reproduzidos, citado, aspeados ou não, dotando a narrativa euclidiana de uma verdadeira polifonia, dramatizada por meio de discursos que se embatem, contraditórios, paradoxais" (MADEIRA, 2004, p. 105). De acordo com Ronaldo Machado, trata-se de uma "[...] narrativa da história da Campanha de Canudos [...] o elemento axial, a partir do qual as dimensões literária e historiográfica, especialmente, se articulam, se interpenetram e se complementam mutuamente" (MACHADO, 2005, p. 94). Bem situada no tempo e no espaço, a narrativa se despoja dos ideais da cidade para o culto da terra em suas dimensões de criação e emanação da vida. A narrativa euclidiana faz jus à afirmação de Dardel, ao dizer que o rigor da ciência não perde nada ao confiar sua mensagem a um observador que sabe admirar, selecionar a imagem justa, luminosa, cambiante (DARDEL, 2011, p. 3). Ele somente dá ao termo concreto seu amparo e sua medida. É pela terra que se denota a origem 
da vida, ou seja, neste caso, da nova vida possível, mesmo enfrentando a guerra - que igualmente se impõe pela posse e domínio da terra e do seu natural habitante. Aliás, é da terra que advém o conhecimento do lutador e de sua resistência, das artimanhas possíveis, não tanto de ataque e mais de defesa, impossibilitando o avançar do inimigo e garantindo-lhe a fixação. Como analisa Machado (2005), existe uma poética da história, ao que nós aqui adaptamos para a poética do espaço e entendemos como configuração de outro aspecto, que é o da formação de uma comunidade dentro de "[...] uma perspectiva integradora onde no mundo, ser humano e as 'coisas do mundo' compõem um único universo integrado pela geopoética [...]" (KOZEL, 2012, p. 66).

Segundo Marcos Rogério Cordeiro, há, em Os Sertões, uma "poética da natureza", na qual o espaço da vida revela os fenômenos da natureza e em unidade e harmonia de forças (CORDEIRO, 2005, p. 109). Não se trata apenas de uma descrição da paisagem, embora o faça com requinte vocabular, mas sim, um cenário constituído de conteúdos e conflitos que compõem a terra. É dela que ele parte para a escrita do romance e dela revela os desequilíbrios e como conviver com eles. A terra inicia o romance para situar o leitor e mostrar o porquê dos acontecimentos vindouros, nela a plenitude do sertão integrando o homem à sua essência. Muito do que pensamos hoje a respeito do sertão nordestino faz parte desta constelação imagética que teve como um dos seus precursores o texto de Euclides da Cunha. A força viva do sertão onde a natureza e o homem transformam-se mutuamente interessa a este olhar amplo e integrador, especialmente numa época em que a pluralidade de vozes e olhares sobre os mais diversos locais por onde tenha passado a existência humana se faz amplificado na poética que se quer sínese das forças que dão aporte a cultura.

No caso do arraial de Canudos, seja para fins de sobrevivência, seja de inovação pelos elementos constitutivos de grupo, a identidade se fortalece, chegando até mesmo a chamar a atenção dos órgãos governamentais sob forma de ameaça ao poder estabelecido. As raízes culturais aliam-se às necessidades de sobrevivência e ampliam-se forças no sentido de assegurar garantias de vida de formas de viver. Com sentidos próprios do grupo em formação e com adoção de normas próprias, sobressai-se a liderança de Antônio Conselheiro, como líder da comunidade em formação. Adotaremos aqui a análise feita por Benedict Andersen (2008) ao referir-se às comunidades imaginadas, no sentido de fazerem sentido para seus integrantes e constituição de objetos de desejo e projeção de sonhos. Para o autor, há um nacionalismo em tais 
comunidades a partir da legitimidade emocional profunda com a intenção de refazer o antigo a partir de uma seleção consciente de uma espécie de fragmentos de memória.

Os Sertões de Euclides da Cunha é um livro "[...] plural desde o título, sobressaindo-se um enfoque interdisciplinar, em que $o$ narrador multiperspectivado desautoriza os estudos norteados por um único ponto de vista" (SOUZA, 2009, p. 9). Nele, filosofia, ciência e poesia coexistem em pé de igualdade. Referências a Thomas Buckle, von Martius, Henry Huxley e Frederick Hartt são seguidas do discurso Hegeliano a respeito das diferenciações étnicas e dos fatores geográficos que incidem sobre o homem, demonstrando através do exemplo o trabalho desenvolvido por estes no intuito de neutralizar a implacável ação da natureza sobre as populações do sertão. Estas referências não acontecem ao acaso. Euclides narrou a terra e o homem sertanejo fazendo emergir do interior árido o sofrimento e a força de um povo abandonado pelas circunstâncias e equívocos dos governantes do período que muitas vezes desconheciam as suas reais necessidades, "[...] visam, de um modo geral, atenuar a última das consequências da seca - a sede; e o que há de combater e a debelar nos sertões do norte - é o deserto" (CUNHA, 1998, p. 63).

Ao contrário da hierarquia eurocentrista que sobrepõe o tempo ao espaço (ECHEVERRI; ARIAS, 2014; SOUZA, 2009), o drama da terra narrado por Euclides da Cunha tem início com uma excursão no espaço e termina com uma incursão no tempo. Ao lançar-se sobre a vastidão do planalto central brasileiro, estabelece as diferenças no relevo, onde "[...] o traço contínuo e dominante das montanhas, precintando-o com destaque saliente, sobre a linha projetante das praias" (CUNHA, 1998, p. 17), vai perdendo sua grandiosidade na medida em que se interioriza ao norte do país. De um lado, a terra que atrai os homens, aquela onde a natureza é diversa. A Serra da Canastra, o Rio das Velhas e o São Francisco são emblemáticos neste aspecto, pois contam a própria história da ocupação do território desde os tempos memoráveis. De outro, em direção ao norte, o Vaza-Barris, rio que abastece as roças e vilas. No seu entorno os povoados e vilarejos minúsculos que acompanham os cursos d'água, fazendo do sertão algo excepcional e selvagem, “[...] estranho território, a menos de quarenta léguas da antiga metrópole, predestinava-se a atravessar absolutamente esquecido os quatrocentos anos de nossa história [...] inabordável, ignoto" (CUNHA, 1998, p. 23), anunciado por Euclides da Cunha como ideia de oposição e de idealização: 
Galgava o topo da favela. Volvia em volta o olhar, para abranger de um lance o conjunto da terra. - E nada mais divisava recordando-lhe os cenários contemplados. Tinha na frente a antítese do que vira. Ali estavam os mesmos acidentes e o mesmo chão, embaixo, fundamente revolto, sob o indumento áspero dos pedregais e caatingas estonadas... [...] E quase compreendia que os matutos crendeiros, de imaginativa ingênua, acreditassem que ‘ali era o céu...'. (CUNHA, 1998, p. 27)

Analista da natureza, Euclides da Cunha investiga e expõe em seu texto a gênese do fenômeno das secas, dando sugestões que mesmo na atualidade poderiam ajudar para diminuir a carestia e a falta d'agua no sertão nordestino (ABREU, 1988). Em suas descrições, a vegetação é bastante valorizada levando-se em consideração as suas respectivas funções diante da aridez do solo: caatingas, capões, cajueiros anões, caroás, nopaleas, cactos, juazeiro, mandacurus, xiquexiques, cabeças-de-frade, quipás, palmatórias-do-inferno, Catanduva, entre outros. Todas demarcam um cenário povoado e caracterizado pela seca, reforçam a dificuldade de vida e a típica vegetação resistindo apesar das condições climáticas desfavoráveis. Ao contrário, a partir de março, quando as chuvas caem, renova-se o cenário:

E ao tornar da travessia o viajante, pasmo, não vê mais o deserto. Sobre o solo, que as amarílis atapetam, ressurge triunfalmente a flora tropical.

É uma mutação de apoteose.

Os mulungus rotundos, à borda das cacimbas cheias, estadeiam a púrpura das largas flores vermelhas, sem esperar pelas folhas; as caraíbas e baraúnas altas refrondescem à margem dos ribeirões refertos; ramalham, ressoantes, os marizeiros esgalhados, à passagem das virações suaves; assomam, vivazes, amortecendo as truncaduras das quebradas, a quixabeiras de folhas pequeninas e frutos que lembram contas de ônix; mais virentes, adensam-se os icozeiros pelas várzeas, sob o ondular festivo das copas dos ouricuris: ondeiam, móveis, avivando a paisagem, acamando-se nos plainos, arredondando as encostas, as moitas floridas do alecrim-dos-tabuleiros, de caules finos e flexíveis; as umburanas perfumam os ares, filtrando-os nas frondes enfolhadas, e dominando a revivescência geral - não já pela altura senão pelo gracioso do porte, os umbuzeiros alevantam dois metros sobre o chão, irradiantes em círculo, os galhos numerosos. (CUNHA, 1998, p. 43) 
Dessa descrição oposta a tudo o que é dito sobre o sertão, o autor revigora-o, enchendo-o de vida pela exuberância da natureza, chegando até mesmo a corroborar com a já mencionada comparação ao céu: "O sertão é um paraíso" (CUNHA, 1998, p. 45). E o ciclo se fecha e o sertão retorna à seca "[...] surdamente, imperceptivelmente, num ritmo maldito, se despeguem, a pouco e pouco, e caíam, as folhas e as flores, e a seca se desenhe outra vez nas ramagens mortas das árvores decíduas [...]" (CUNHA, 1998, p. 46). E, neste vai-e-vem das chuvas e secas o sertão se alterna, provocando necessidades diversas e influenciando no ânimo do sertanejo, fazendo-o enfrentar alterações vitais para a existência. Assim, os grupos buscam sobrevivência conforme a condição apresentada, tanto na seca quanto nas chuvas, há dificuldades a serem enfrentadas e cada situação faz repensar o espaço e o modo de vida nos sertões do norte, "Barbaramente estéreis; maravilhosamente exuberantes [...]" (CUNHA, 1998, p. 47). O reforço posto nos adjetivos e advérbios enaltece tanto os aspectos bons quanto os ruins do clima e, principalmente, eleva a força do homem sertanejo diante dos extremos de sua terra. $E$ as oposições seguem em toda a narrativa: "A natureza compraz-se em um jogo de antíteses" (CUNHA, 1998, p. 48). Trata-se de uma terra mais conhecida pela seca, porém convive com períodos de enchentes e deixa o povo à mercê de intensidades extremas, para as quais a força humana integra-se à da terra para conviverem lutando juntos. O homem liga-se à terra para criarem uma comunidade estreita e de sobrevivências. Não é ele que a determina e sim, ao contrário, o sertanejo habitua-se de tal forma com as vicissitudes que, ao trocar o clima, adapta-se a ele mesmo com as mais horrendas dificuldades. E é essa resiliência que o faz um forte e um desbravador. Ao não abandonar a terra, procura entendê-la, adaptar-se e conviver com ela, é dela o sustento e também a luta alternada de tempos em tempos e tratada conforme a necessidade do momento: "Da extrema aridez à exuberância extrema [...]" (CUNHA, 1998, p. 49). Em sua narrativa, por mais difícil que possa parecer nunca a terra é rejeitada tampouco abandonada pelo sertanejo, apenas tratada e enfrentada em toda a exuberância e vontade de viver. Tal qual um paisagista,

[...] monumentaliza o sertão e suas chapadas, numa volumetria iluminada, escultórica e cenográfica, uma nova explosão da luz, uma nova organização dos planos que se chocam e se dissolvem dando a ilusão do mar, realizando a profecia do conselheiro. $\mathrm{O}$ narrador registra também as paisagens intimistas, riachos e plantas rasteiras, na tentativa de captar a totalidade do sertão, ou o sertão como uma totalidade. (MADEIRA, 2004, p. 123). 
É pela terra que a comunidade se fortalece no Arraial de Canudos, no interior da Bahia, local da narrativa de Euclides da Cunha. O estilo e os recursos tornam a comunidade exitosa como forma de existência em lugar tão inóspito. A sua existência em um local tão isolado protege-os de influências externas e de outras formas de organização social. Ali importava manterem-se unidos, com "estruturas de camaradagem horizontal" (SCHWARCZ, 2008, p. 12). Todo o episódio de Canudos ganhou relevo e tornou-se conhecido a partir das anotações de Euclides da Cunha ao chamar-lhe a atenção aquele aglomerado de pessoas que foram se formando próximos ao seu trabalho de engenharia na construção de uma ponte em 1896. Despretensiosamente, a princípio, ele observava e anotava tanto o que via quanto suas impressões sobre o que via. Ao enviar para publicação no jornal O Estado de São Paulo, duas matérias sobre o episódio que se tornou conhecido como A Guerra de Canudos, Euclides da Cunha trouxe à tona não apenas um conflito mas a relação das pessoas com o seu espaço e suas lutas. Seus relatos estabeleceram contiguidade quanto à luta daquele povoado ao tornar conhecimento público um conflito particular de uma região. A construção coletiva, de caráter popular, surpreendeu e evidenciou a possibilidade de assim organizar-se, o que não agradou aos governantes locais. A solidez da comunidade incentivou-os ao fortalecimento de ideais e prosseguimento na luta. Em relação a Euclides da Cunha, Madeira salienta que:

Ao chegar ao local e descobrir um Brasil que desconhecia completamente, fica aturdido. Como intelectual urbano, com sua formação científica e ateia, compartilhando crenças positivistas, percebe que havia se equivocado e não sabe como interpretar aquele recanto ignora do país - "terra ignota", diz em seu latim alarmado! -, e muito menos uma guerra religiosa conduzida por um líder carismático. Percebeu o fosso que separava as massas urbanas, conduzidas pelo credo contiano da ordem e do progresso, adotado pela República, dos sertanejos seminômades que viviam na total desinformação do que se passava nas "Terras Grandes", de onde, no entanto, partiam as decisões - impostos, leis - que lhes afetavam a vida e os valores. Estas posições antagônicas são também estruturantes de campos discursivos que exprimem o jogo dos conflitos presente em Os sertões. É neste contexto que se insere a obra de Euclides da Cunha, que apanha, no nível da própria linguagem, esse feixe de contradições, como um projeto de estabelecer alguma forma de mediação e de incluir aquela população na história. (MADEIRA, 2004, p. 103). 
Todos os objetivos de vida em Canudos se resumiam, principalmente, à terra. Por ela, a luta se intensificou e adquiriu proporções, resistindo ao poder constituído dando vasão à formação de novo poder local, mais autêntico e com causas melhor justificadas. Neste caso, a territorialidade impõe-se sob a forma de crença e reitera a ideia de "pátria imaginada" (FERREIRA, 2011, p. 171). Temos, portanto, que neste território há um desenvolvimento próprio de ações movidas por ideologias e objetivos a serem alcançados. Trata-se de um "[...] produto da apropriação/valorização simbólica de um grupo em relação ao seu espaço vivido [...]. Ou seja, a dimensão simbólica habita um espaço social, organizando-se pela historicidade e geograficidade, quesitos de territorialidade" (FERREIRA, 2011, p. 174). É pelas vertentes históricas e geográficas que se solidifica a autenticação do grupo dada pela geografia cultural e simbólica do grupo ali constituído. Do espaço imaginado ao espaço real há um povo se desenvolvendo e solidificando propósitos, da ficção euclidiana para a realidade de Canudos há um movimento cultural que congrega pessoas vindas de várias partes do sertão, unidas pela necessidade $\mathrm{e}$ pela vontade de construir um lugar que os aceite, no qual possam construir suas vidas dignamente. Uma pátria imaginada a partir do princípio da igualdade e da luta pelos obstáculos enfrentados pela terra e sua oposições já mencionadas.

Analisando do ponto de vista da influência do espaço sobre o indivíduo ou grupo, tomaremos como princípio a construção identitário-territorial de Rogério Haesbaert quanto à "[...] admitir que a própria construção das identidades espaciais - ou territoriais - irá adquirir feições diversas de acordo com a concepção de espaço à qual estiver vinculada" (HAESBAERT, 2011, p. 47). É no espaço definido e determinado que as pessoas ali residentes se constituirão como grupo e se identificarão nas suas concepções de modo de vida. Com o intuito de se firmar na terra que lhes acolheu, fazem do cotidiano um jeito de afinarem constructos de formação pessoal e de grupo. Processos identitários surgem naturalmente por ações involuntárias simplesmente porque estão juntos com propósitos afins que se encaminham para a sobrevivência. Não há alternativas fora do grupo, uma vez que surgiu para cumprir determinadas expectativas e construções. É assim que o texto euclidiano se encaminha para a integração do povo de Canudos, pela interação nos atos ritualizados pela crença e pela empatia a Antônio Conselheiro com suas leituras bíblicas. Em relação à construção de uma identidade a respeito do nordeste, muito se deve as circunstâncias com que este foi construído material e simbolicamente em especial nas primeiras décadas do século XX, tendo por 
base uma série de referências literárias e mesmo imagéticas sobre a região. Neste sentido, Albuquerque Júnior adverte-nos que:

Longe de considerar esta região como inscrita na natureza, definida geograficamente ou regionalizada "pelo desenvolvimento do capitalismo, com a regionalização das relações de produção", que é outra forma de naturalização, ele buscou pensar o Nordeste como uma identidade espacial, construída em um preciso momento histórico, final da primeira década deste século e na segunda década, como produto do entrecruzamento de práticas e discursos "regionalistas". Esta formulação, Nordeste, dar-se-á a partir do agrupamento conceitual de uma série de experiências, erigidas como caracterizadoras deste espaço e de uma identidade regional. Estas experiências históricas serão agrupadas, fundadas num discurso teórico, que pretende ser o conhecimento da região em sua essência, em seus traços definidores e que articula uma dispersão de experiências cotidianas, sejam dos vencedores, seja dos vencidos, com fragmentos de memórias de situações passadas, que são tomadas como prenunciadoras do momento que se vive, de "ápice da consciência regional". (ALBUQUERQUE JR, 2000, p. 11)

Neste sentido temos que o espaço, se produz socialmente e estabelece relações de poder de acordo com as situações ali constituídas e necessidades do grupo social no espaço habitado: "[...] toda identidade, a exemplo de qualquer processo social, tem uma dimensão espacial - pelo simples fato de que não se realiza puramente 'em abstrato' [...] mas contextualizada no espaço-tempo, geográfica e historicamente percebido/vivido" (HAESBAERT, 2011 , p. 51). A identidade passa a ocorrer no texto euclidiano na medida em que há identificação entre as pessoas e se reúnem em espaço delimitado, formando uma comunidade de fato, atuando em determinado momento histórico e marcando posições e atitudes. Há, neste caso, uma representação 
homogênea estabelecida e constituída no espaço identitário marcado pela dificuldade do clima pelas secas e pelas chuvas intensas. Daí surge a autenticidade do grupo, sua luta vira símbolo de resistência e de formação de novas formas de convivência. Estratégias envolvendo crença religiosa surgem no decorrer da narrativa a fim de solidificar o grupo como tal e deixar sua marca na sociedade. A causa da luta passa a ser de ordem subjetiva e de identificação a partir da necessidade de resolver questões sociais surgidas do local: a pobreza e a falta de condições dignas de vida ocasiona a reunião das pessoas que passam a aglutinar-se em um povoado, despertando a atenção dos poderes governamentais e trazendo a guerra para junto de si. Neste espaço tentam criar um lugar ideal para se viver, mesmo participando de dificuldades diariamente: "O martírio do homem, ali, é o reflexo de tortura maior, mais ampla, abrangendo a economia geral da vida. Nasce do martírio secular da Terra [...]" (CUNHA, 1998, p. 55).

\section{CONSIDERAÇÕES FINAIS}

Publicado no início do século XX, Os sertões não perdeu sua força ao narrar uma experiência inquietante onde um dos locais mais recônditos do território nacional é desvelado juntamente com sua gente ao restante da população. Ao contrário do que muitos diziam - e dizem ainda hoje - não é o clima por si só que nos explica a situação do nordeste brasileiro. Inequivocamente avassalador, moldando e sendo moldado na lida diária dos sertanejos, homens e mulheres que se sobressaem diante da adversidade ao qual são submetidos, ele é ultrapassado no texto de Euclides da Cunha que ao abrir mão do discurso rasteiro vai ao âmago do problema social, o abandono ao qual estas populações foram - e são - relegadas. A ausência do Estado de outrora e o discurso que inaugura a indústria da seca como se a natureza por si só fosse encarregada de manter inalteradas as estruturas sociais e econômicas responsáveis pelas desigualdades na região. Ao contrário disso, temos em Os sertões o relato sobre uma natureza que se transforma em ciclos, onde a terra se refaz como fonte de unidade cultural e de vida. Local inóspito muitas vezes, quase impossível à presença humana, sob o olhar do autor sobressai-se através das pedras e das arvores de galhos retorcidos. A caatinga que, ricamente descrita dá-nos a impressão ou mesmo a certeza de que a reprodução material da vida diária é possível para os filhos da terra, é apresentada na geopoética que integra o homem a sua essência, eternizada nas linhas vigorosas da narrativa euclidiana. 
Impactado pelos acontecimentos, Euclides mudou seus conceitos a respeito do lugar e das pessoas. Já não eram mais meramente matutos rústicos e relutantes diante das transformações por que passava o país. Não se tratava apenas de um local inóspito que a todos subjugava. São "patrícios", são "brasileiros", relegados à própria sorte no sertão nordestino. Mas porque isso foi possível? Esta é a grande questão que se impõe e que possibilita que o narrador sobrevoe a região e nos apresente uma terra diferente daquela que esperava encontrar quando se deslocou do Rio de Janeiro para o interior baiano. A unidade harmoniosa da natureza é intensa não apenas em sua beleza, mas também na força com que atua sobre as populações. Por vezes de forma conflituosa, transforma e deixa-se transformar dando vida e forma as expressões primordiais da cultura sertaneja. Cultura que emerge de comunidades reais e imaginadas na crença de que é possível ser e pertencer no ideal e no sonho comum de uma vida digna onde as necessidades básicas possam ser atendidas.

Resiliente, o sertanejo não abandona a terra, adapta-se, convive com ela. Em Canudos acreditam poder viver em comunidade e nela vencer as intempéries climáticas. Foram fortes porque a terra era forte, e não mediram esforços para fazer valer os princípios que os guiaram das mais diversas localidades da região para aquele lugar em especial. Forjaram sua própria identidade no trabalho e na fé, lutando pela terra que os mantinha unidos. Terra de flores e galhos retorcidos, de seca e de enxurrada, de horizonte que une o céu na montanha em meio o serpentear de trilhas percorridas por aqueles que buscavam mais do que a água e o pão que alimenta e mantem o corpo, queriam pertencer e sentirem-se acolhidos, ser parte de algo maior, que thes resguardasse e que não tivessem que deixar o sertão onde nasceram.

Uma das grandes virtudes do texto em questão é justamente o fato de sobressair-se ao formalismo da escrita técnica e científica, pintando com múltiplas cores o cenário repleto de rios, montanhas, plantas e desertos, onde o clima oscila, muda, se transforma, contradiz-se a cada novo ciclo da natureza. Repleto de Antítese! É o sertão um paraíso? Talvez sim, talvez não, mas uma vez desenhado com palavras ganha a exuberância da vida, e isso, depois de Euclides da Cunha, ninguém mais pode lhe retirar. 


\section{REFERÊNCIAS}

ABREU, Modesto de. Estilo e personalidade de Euclides da Cunha (2 ed.). Rio de Janeiro: Academia de Letras, 1988.

ALBUQUERQUE JR., Durval Muniz de. "Um leque que respira: Michel Foucault e a questão do objeto em história". In PORTOCARRERO, Vera, CASTELO BRANCO, Guilherme (Orgs.), Retratos de Foucault, Rio de Janeiro: NAU, 2000, pp. 117-137.

BOUVET, Rachel. "Du parcours nomade à l'errance: une figure de l'entredeux". In BOUVET, Rachel, CARPENTIER, André et CHARTIER, Daniel, Nomades, voyageurs, explorateurs, deambulateurs - Les modalités du parcours dans la literature, Paris, France : L'Harmattan, 2006, pp. 35-50.

CARVAlHO, José Murilo de. Os bestializados: o Rio de Janeiro e a República que não foi. São Paulo: Compaanhia das Letras, 1987.

CHAUI, Marilena. Brasil: mito fundador e sociedade autoritária (4 ed.). São Paulo: Editora Fundação Perseu Abramo, 2001.

CORDEIRO, Marcos Rogério. "A poética da natureza em Os sertões". In GOMES, Gínia Maria, Euclides da Cunha, Porto Alegre: Editora da UFRGS, 2005, pp. 105-121.

CUNHA, Euclides da. Os Sertões. São Paulo: Editora Ática, 1998.

DARDEL, Eric. O homem e a terra: natureza da realidade geográfica. São Paulo: Perspectiva, 2011.

ECHEVERRI, Ana Patricia Noguera de, ARIAS, Diana Alexandra Bernal. "Geografías del habitar. Um habitar geopético em la era planetária". Geograficidade. v. 4, n. ${ }^{\circ}$, pp. 19-31. Inverno 2014.

FERREIRA, Dina Maria Martins. "Interculturalidade e territorialidade: 'uma pátria imaginada' ?". In BASTOS, Liliana Cabral, LOPES, Luiz Paulo da Moita (Orgs.), Estudos de identidade - entre saberes e práticas, Rio de Janeiro: Garamond, 2011, pp. 171-184.

HAESBAERT, Rogério. "O espaço importa: dilemas da construção identitário-territorial na contemporaneidade". In BASTOS, Liliana Cabral, 
LOPES, Luiz Paulo da Moita (Orgs.), Estudos de identidade - entre saberes e práticas, Rio de Janeiro: Garamond, 2011, pp. 45-76.

KOZEL, Salete. "Geopoética das paisagens: olhar, sentir e ouvir a "natureza"'. Caderno de Geografia, v. 22, n 37, pp. 65-78, jan-jun 2012.

MACHADO, Ronaldo. "A narrativa da história em Os Sertões". In GOMES, Gínia Maria (Org), Euclides da Cunha: literatura e história, Porto Alegre: Editora da UFRGS, 2005, pp. 93-108.

MADEIRA, Angélica. "Fraturas do Brasil: o pensamento e a poética de Euclides da Cunha". In AXT, Gunter, SCHÜLER, Fernando Luis, Intérpretes do Brasil, Porto Alegre: Artes e ofícios, 2004.

MIR, Luís. Guerra civil: Estado e trauma. São Paulo: Geração Editorial, 2004.

OLIVEIRA, Ricardo. "Euclides da Cunha. Os Sertões e a invenção de um Brasil profundo". Revista Brasileira de História, São Paulo, v. 22, n 44, pp. 511-537, 2002.

SOUZA, Licia Soares de. "Fiç̧ão e História em A guerra de Canudos". Especiaria (UESC), v. 10, pp. 77-90, 2007.

SOUZA, Licia Soares de. "Géopoétique et Métissage". 20 anos de interfaces Brasil-Canadá, Salvador: EDUFBa., 2012.

SOUZA, Ronaldes Melo. A geopoética de Euclides da Cunha. Rio de Janeiro: EdUERJ, 2009. 